\title{
IDENTIFICATION OF MULTIPLE BUBBLES IN TURKISH FINANCIAL MARKETS: EVIDENCE FROM GSADF APPROACH
}

\author{
FINANSAL PIIYASALARDA VARLIK BALONU İNCELENMESİ: GSADF \\ YAKLAŞIMI
}

Remzi GÖK ${ }^{*}$ iD

\begin{abstract}
This study examines the explosive behavior in the five local market prices of stock indices (in USD and TRY), bond, CDS, gold, and currency exchange rate of USDTRY at weekly observations over the sample period between 2005 and 2021. We find strong evidence of bubble formations in bond, gold, and currency markets during the crisis (financial and pandemic, such as ongoing COVID-19 outbreak) and non-crisis periods. The findings show both unidirectional and bidirectional causal linkages under the homoscedasticity and heteroscedasticity assumptions. Additionally, the causation is most pronounced under the homoscedastic model between the currency market with the CDS, gold, and stock markets.
\end{abstract}

Keywords: Bubbles, GSADF, Recursive Evolving Causality, COVID-19, Contagion

JEL Classification: C58, G11, G12.

Öz

2005 ve 2021 yılları arasındaki dönemin dikkate alındığı bu çalışmada, hisse senedi (TL ve dolar bazında), tahvil, CDS, altın ve döviz gibi beş farklı finansal piyasanın haftalık frekansta kapanış fiyatları kullanılarak, bu fiyatlarda balon varlığı incelenmiştir. Hem finansal ve salgın dönemini içeren kriz, hem de kriz dışı periyotlarında geçerli olmak üzere altın, CDS ve tahvil piyasalarında fiyatlarda balon oluşumunu gösteren anlamlı bulgular elde edilmiştir. Bulgulara göre homoskedastik ve heteroskedastik modellerinde tek ve çift yönlü olmak üzere nedensellik ilişkilerine rastlanmıştır. Bu ilişkinin en çok CDS, altın ve hisse senedi piyasaları ile döviz piyasası arasındaki homoskedastik varsayımların geçerli olduğu model altında belirginleşmektedir.

Anahtar Kelimeler: Varlık Balonu, GSADF, Hareketli Nedensellik, COVID-19, Bulaşma.

JEL Sinıflandırması: C58, G11, G12.

* Dr., Dicle University, Faculty of Economics and Administrative Sciences, Department of Business Administration, Sur, Diyarbakır. E-mail: remzi.gok@dicle.edu.tr, ORCID ID: 0000-0002-9216-5210 


\section{Introduction}

Asset price bubbles in financial markets have been receiving tremendous attention among policymakers, academics, and the public because of their devastating effects on financial markets, the real economy, and wealth. Therefore, determining whether or not they exist and when their adverse effects will end is of great importance in terms of appropriate policy construction and portfolio management decisions. In literature, the debated questions are the pricing of assets, categorizing price movements, and determining the most suitable econometric approach in identifying bubble like-characteristics.

In their pioneering study, Blanchard and Watson (1982) argue that economists have been wrong about the pricing of assets depending on fundamentals of a stream of cash flows and discount rates given the assumption of rational expectations and rational behavior of investors; therefore, an asset price can rationally deviate from its fundamental price. A rational bubble can be defined, as in Diba and Grossman (1988), as a self-confirming divergence of asset (stock) prices from market fundamentals in response to external variables. Blanchard and Watson (1982) indicate that the probability of bubble formation in a (gold) market may be higher than in other markets (such as stock) due to the degree of difficulty in correctly assessing the fundamentals affecting the price. They also highlight the fact that the effect of a bubble is not only limited to that market but will also affect other markets.

In the paper of Brunnermeier (2008), the author divides the bubble literature into four groups of models in terms of identifying conditions under which bubbles can exist. In the first category, all investors are assumed to be rational and symmetrically informed whereas in the second category, they have a different level of knowledge and bubbles can arise because their existence need not be widely known. Apparently, these two groups of models are similar in terms of investors' expectations but differ when it comes to assumptions for the distribution of information. In the third category, however, theoreticians focus on the interaction of rational and irrational investors with each other. According to these models, the rationale behind the persistence of a bubble in markets is the arbitrage limitations on rational investors. The models in the fourth category, on the other hand, point to the heterogeneity of investor beliefs, because of psychological biases, and therefore, accept the existence of divergence from fundamental prices.

Bubbles follow a succession of phases as the business cycle does. Asset prices are inclined to rise during the first phase (developing) and escalate at an increasing rate during the second phase (booming). ElMontasser et al. (2016) point out that the prices during these phases generate expectations of further rises and attract new buyers. The prices, however, reach a peak in the third phase (peak) and, then, start contracting at the final phase. Rational investors benefit from every stage of the process while sophisticated investors wait for a convenient time to close out their positions. Latecomers, however, may suffer losses because they try to catch a falling knife. The effects of the collapse of rational bubbles are worse for the economy as well as for individual investors (Nazir et al., 2019). As stated by Balcilar et al. (2016), market agents sustain a belief that buying additional units is still profitable, despite being overvalued concerning their fundamentals, as they do not miss any opportunity to 
make a profit. A rational intrinsic bubble emerges on the condition that prices rationally deviate from their fundamentals and form a bubble due to changes in investors' sentiments (Froot and Obstfeld, 1991). Alternatively, a speculative or irrational bubble emerges due to the self-fulfilling beliefs of investors, who fail to correctly and timely identify the bubble phases and indulge in herding (Tran, 2017).

The unpredictability of bubbles and their potential to cause serious economic damage have been the subject of studies in which researchers have used various empirical approaches. As discussed in the papers of Gürkaynak (2008) and Homm and Breitung (2012), the relevant list includes the variance bound test (Shiller, 1981), two-step test (West, 1987), cointegration-based test (Diba and Grossman, 1988), the concept of intrinsic bubbles (Froot and Obstfeld, 1991), and the Markov-Switching Augmented Dickey-Fuller (DF) test (Hall et al., 1999) to identify bubble formations in markets. Of these tests, the variance bound test and two-step tests have been rigorously criticized by Evans (1991) because of their drawbacks in detecting periodically collapsing bubbles.

Phillips et al. (2011, PWY hereafter) and Phillips et al. (2015, PSY hereafter) proposed a supremum DF to overcome the limitations of the aforementioned tests. The test has been widely used by researchers for studying bubble detection in financial markets. For instance, a voluminous literature provides significant evidence in support of the presence of bubbles in stock markets (Chan et al., 2003; Gomez-Gonzalez et al., 2017; He et al., 2019) and against the unit root hypothesis (Deev et al., 2014; Yu and Hassan, 2010) for other than the Turkish stock markets. Regarding the Turkish stock indices, conversely, the findings are mixed, namely, the markets may show evidence of rational bubbles (Zeren and Yilanci, 2019) or not (Yanik and Aytürk, 2011).

There is also vast literature on bubble detection and estimation in currency markets. This list includes the papers of Evans (1986), Maldonado et al. (2019), Meese (1986), and Pavlidis et al. (2017) in favor of bubble existence, and West (1987), Wu (1995), and Bettendorf and Chen (2013) against the presence of bubbles in foreign exchange markets. Among these papers, Jirasakuldech et al. (2006) find nonexplosiveness in GDPUSD, USDCAD, USDDKK, USDJPY, and USDZAR at monthly frequency using unit root, cointegration, and duration tests during the sample period 1989-2004. Jiang et al. (2015), on the other hand, document significant results in the USDCNY rate after 2005 as the exchange rate was under a managed floating exchange rate regime. The authors present evidence of two bubbles; the first bubble emerged during 2005-2006 and the second one appeared during the global financial crisis. The same results were obtained by Elike and Anoruo (2017), who provide significant evidence of explosive bubbles in the nominal USDZAR rate, the real exchange rate of traded and non-traded goods. Korkmaz et al. (2016) revealed significant evidence in favor of the bubble existence in stock index returns of Bist100, gold, and USDTRY foreign exchange rates, whereas the result was insignificant for the deposit interest rates and EURTRY exchange rates in Turkey. They stated that the existence of bubbles in gold prices has significantly negative impacts on the stock index volatility, whereas the result is negative, albeit not significant for the USDTRY foreign exchange rates. 
In retrospect of the literature, there is a bulk of research papers on bubble existence in gold markets, including Baur and Glover (2012), Bertus and Stanhouse (2001), Bialkowski et al. (2015), Çelik et al. (2019), Diba and Grossman (1984), and Korkmaz (2018). All of these papers, except for Korkmaz (2018), provide significant evidence in support of the presence of bubbles in the gold prices during notable historical events, confirming the role of gold as a safe-haven during the periods of turmoil. Among these papers, Baur and Glover (2012) showed that the gold markets have been dominated by chartists (feedback traders) and concluded that real demand for gold had dropped relative to investment demand. Bialkowski et al. (2015), on the other hand, concluded that it was not necessary to resort to the irrational bubble explanation to elucidate the significant fluctuations observed in the market.

In retrospect of the literature, however, the number of studies on bubbles in the bond and CDS markets, compared to other markets, is relatively scarce. Phillips and Yu (2011) documented bubble migrations from housing markets to first oil and then to bond markets. The bubble in bond markets, however, originated on September 22, 2008, corresponding to the Lehman Brothers bankruptcy, and collapsed on April 4, 2009, when the global economic implications of the crisis became evident. Huston and Spencer (2018) found that the explosive increase in monetary supply through quantitative easing had fueled bond prices after the crisis period, such as in 2011-2013 and 2016, suggesting multiple bubbles in the market. Similarly, Chiu and Yeh (2019) stated that budget deficits, contractionary monetary policy, and oil shocks gave rise to multiple bubble existence in the government bond markets in developed countries. On the other hand, Oliveira and Santos (2015), using daily observations for 5-year maturity Greek sovereign credit default swaps (SCDSs), reported clear evidence of bubble existence in SCDSs spreads during the sample period between September 2014 and March 2015, driven by the financial and political anxiety in Greece.

Although the pandemic crisis is not over yet, but its effect gradually decreases, literature that investigates the existence of price exuberance in the financial markets during the pandemic outbreak is scarce. For instance, Gharib et al. (2021) investigated the impact of the COVID-19 outbreak on the causal relationship between the WTI and gold prices. They detected evidence of mildly explosive episodes and a two-sided contagion effect of bubbles in both markets during the periods of the pandemic crisis. Using hourly exchange rate data of four currencies (EURO, GBP, YEN, and CAD), Narayan (2020) found no evidence of explosiveness in the foreign exchange rates of EURO, GBP, and YEN, but the test rejected the null of no existence of a bubble in CAD before the COVID-19 period (2019M07-2019M12). However, the author put in evidence in favor of the existence of a price bubble in GBP, YEN, and CAD during the COVID-19 period (2020M01-2020M09), implying an increased market efficiency due to intensified bubble activities in the pandemic period. Jalan et al. (2021) examined the stock market performance of 43 firms in six industries, exhibiting sharp price increases during the COVID-19 period, using daily close-price observations covering November 2019 to January 2021. The results suggested the presence of rational bubbles in almost all industries, including "Bitcoin companies", "Coronavirus therapeutics companies", "Coronavirus Vaccine companies", "Cryptocurrency companies", "stay-at-home companies", and "work-fromhome companies". "Bitcoin" and "stay-at-home companies" showed the largest average bubble length, while "Coronavirus-Vaccine" and "Cryptocurrency companies" documented the lowest. Ural (2021) 
studied the existence of price bubble formations in nominal USDKZT exchange rates, using the GSDAF test for the sample period extending from 2015M08 to 2021M04 at a weekly frequency. The author detected two explosive bubbles, one of which originated on July 209, 2018, and burst on September 16, 2018, and the second bubble episode started on March 8, 2020, and ended on April 5, 2020. The author stated that these bubbles might be attributed to (i) the US sanctions on Turkey and the increased inflation (interest) rates and (ii) the oil price war between Russia and Saudi Arabia and the oil's historic plunge with the onset of the COVID-19 outbreak, respectively.

The static or rolling/time-varying causal relationship between financial markets has been well documented in the existing literature. For example, Gök (2020) studied the dependence and causal linkages among stock, bond, CDS, currency, and gold markets in Turkey using both wavelet coherency and the Granger causality-in-variance test. The findings showed both unidirectional and bidirectional causalities during normal and tranquil periods. Using a bootstrap time-varying causality method, Gök and Kara (2021) reveal that the causal linkages among CDS, interest, and currency rates were strong but not homogenous during crisis and non-crisis periods. There was a time-varying but unidirectional causality from the bond to currency markets and bidirectional causality between the pairs of CDS-currency markets and CDS-bond markets during the ongoing pandemic crisis. In another noteworthy empirical study, Gök and Çankal (2020) examined the bondstock market relationship at the aggregate and sectoral levels and found that both market returns were significant predictors of each other in the medium and long time horizons and there was a one-way causality from the negative shocks in stock prices to the positive shocks in interest rates. No causality, however, was found by Noorie et al. (2020) among stock, CDS, and bond markets in Turkey. Hassan et al. (2017), on the other hand, investigated the CDS-currency market relationship in Turkey employing both the rolling window causality and the Markov Switching VAR methods during the period 2009-2015. The findings showed a one-way causal linkage from the CDS spreads to the USDTRY exchange rates in the post-crisis period, that is, during the period of stability in both markets in 2012 while the strength of causality differed according to the regime. Kanda et al. (2018) studied the dynamics of the causal interaction between currency and stock markets in the U.K. for the period 1791-2017. By utilizing the DCC-MGACRH based rolling causality test, they found evidence of time-varying information spillovers between the market returns, supporting either the flow-oriented, stock-oriented model or both models.

The results aforementioned showed that the empirical studies examining the presence of explosive behaviors in and causal interaction between the financial markets during both tranquil and turmoil periods are relatively scarce. To fill this gap in the literature, we study the existence of bubbles and the time-varying causality relationships among selected financial markets in Turkey. This paper complements the empirical literature in two major ways. First, it includes a larger data sample using weekly averages of five financial markets, including stock, bond, CDS, gold, and currency markets, in terms of local currency and USD (for only two stock indices) in Turkey, considering both local and non-resident investors. Second, it does not only consider the detected bubble episodes by either local or/and global crisis periods, but it also employs the recursive evolving causality test to identify the 
contagion effect of bubbles in the financial markets following the procedure in Gharib et al. (2021) and Zhao et al. (2021).

This paper uses the GSADF test of PSY to identify bubbles in five Turkish markets over the period 2005-2021 at a weekly frequency. The results reveal multiple bubble existence in only three out of eight variables. The recursive evolving causality test results show both unidirectional and bidirectional causal linkages under the homoscedastic and heteroscedastic assumptions. The causation is most pronounced under the homoscedastic model between the currency market with CDS, gold, and stock markets.

The layout of the study proceeds as follows. The following section describes the data and briefly introduces the relevant literature regarding the GSADF and the rolling recursive evolving causality tests. In section three, we discuss the empirical findings. Section four concludes the paper.

\section{Data and Methodology}

\subsection{Data}

To investigate the existence of bubbles in Turkish financial markets, we used weekly average closing prices of two stock indices, XU100 and XBANK, both in terms of TRY and USD, and bond (2-year), CDS (5-year dollar-denominated sovereign CDS premiums), gold (per ounce in TRY), and currency market (USD against Turkish Liras, USDTRY). Considering that a bubble can be both the cause and the result of the crisis and for reasons of data availability, we start the sample period in mid-2005, i.e. it started in the second week of April 2005 and ended in the last week of June 2021, with 848 observations. The variables of stock indices and USDTRY were obtained from the Central Bank of the Republic of Turkey (CBRT) EVDS Statistics database while the 2-year Turkish government bond yields and CDS spreads were retrieved from Bloomberg. Gold prices were available from the World Gold Council website. In Table 1, we present descriptive statistics of the continuously compounding returns.

Table 1 reveals that all variables, with the exceptions of XU100_\$ and XBANK_\$ posted positive average weekly performance during the sample period and that GOLD had the highest average return $(0.39 \%)$ followed in turn by USDTRY $(0.22 \%)$ and XU100_TRY $(0.20 \%)$. The CDS spread changes showed the highest volatility (6.67\%) for the underlying Turkish financial markets with a minimum (-44.8\%) and maximum value (37.3\%) found during the financial crisis of 2007-2009 and the COVID-19 pandemic, respectively. On the other hand, the results of the Jarque-Berra (JB) test rejected the assumption of normality with a significantly negative or positive skewness and significantly positive excess kurtosis. 
Table 1: Descriptive Statistics for Return Series

\begin{tabular}{cccccccc}
\hline Variables & Mean & Maximum & Minimum & SD & Skewness & Kurtosis & JB \\
\hline XU100_T & 0.002 & 0.0964 & -0.1537 & 0.0309 & $-1.02^{* * *}$ & $3.03^{* * *}$ & $470.23^{* * *}$ \\
XBANK_T & 0.0011 & 0.156 & -0.1843 & 0.0403 & $-0.6^{* * *}$ & $2.09^{* * *}$ & $205.09^{* * *}$ \\
XU100_\$ & -0.0002 & 0.1529 & -0.2482 & 0.0424 & $-1.11^{* * *}$ & $4.42^{* * *}$ & $863.79^{* * *}$ \\
XBANK_\$ & -0.0011 & 0.1899 & -0.34 & 0.0514 & $-0.87^{* * *}$ & $4.18^{* * *}$ & $722.01^{* * *}$ \\
BOND2 & 0 & 0.1692 & -0.2982 & 0.033 & $-0.36^{* * *}$ & $9.83^{* * *}$ & $3429.67^{* * *}$ \\
CDS & 0.0002 & 0.373 & -0.4483 & 0.0667 & $0.47^{* * *}$ & $5.34^{* * *}$ & $1036.76^{* * *}$ \\
GOLD & 0.0039 & 0.1077 & -0.1117 & 0.0229 & $0.21^{* *}$ & $2.77^{* * *}$ & $277.76^{* * *}$ \\
USDTRY & 0.0022 & 0.1791 & -0.0786 & 0.0173 & $1.84^{* * *}$ & $15.94^{* * *}$ & $9439.62^{* * *}$ \\
\hline
\end{tabular}

Note: ${ }^{* * *}$ denotes rejection of the null hypothesis at the $1 \%$ and $5 \%$ significance levels, respectively. XU100_\$ (1986-0207=100) and XBANK_\$ (1997-01-02=100) indices were calculated using the weekly average of USDTRY rates.

\subsection{Methodology}

For brevity, this paper omits the mathematical details of two well-known methods applied here (GSADF and unit root test) and the readers are referred to Phillips et al. (2015) and Harvey et al. (2016).

To investigate the time-varying causality relationship among five financial market prices, we implement the recursive evolving causality test proposed by Shi et al. (2018). The starting point for this method can be written by an unrestricted $\operatorname{VAR}(p)$ in a multivariate regression format as

$$
\boldsymbol{y}_{\boldsymbol{t}}=\Pi \boldsymbol{x}_{\boldsymbol{t}}+\varepsilon_{t}, \quad t=1, \ldots, T
$$

where $y_{t}=\left(y_{1 t} y 2_{t}\right)^{\prime}, \boldsymbol{x}_{\boldsymbol{t}}=\left(1, y_{t-1}^{\prime}, y_{t-2}^{\prime}, \ldots, y_{t-p}^{\prime}\right)^{\prime}, \quad$ and $\quad \Pi_{2 \mathrm{x}(2 p+1)}=\left[\Psi_{0}, \Psi_{1}, \ldots, \Psi_{p}\right]$. Also, $\widehat{\omega}=T^{-1} \sum_{t=1}^{T} \hat{\varepsilon}_{t} \hat{\varepsilon}_{t}^{\prime}$ with $\hat{\varepsilon}_{t}=\boldsymbol{y}_{\boldsymbol{t}}-\Pi \boldsymbol{x}_{\boldsymbol{t}}$ ( $\widehat{\Pi}$ is the ordinary least squares estimator of $\Pi$ ), and $\mathrm{X}^{\prime}=\left[\mathrm{x}_{1}, \ldots, \mathrm{x}_{T}\right]$ is the observation matrix of the regressors. For the hypothesis testing, $H_{0}: y_{2 t} \rightarrow y_{1 t}$, the Wald test takes the following form

$$
\mathcal{W}=[\boldsymbol{R} \operatorname{vec}(\widehat{\Pi})]^{\prime}\left[\boldsymbol{R}\left(\widehat{\omega} \otimes\left(\boldsymbol{X}^{\prime} \boldsymbol{X}\right)^{-1}\right) \boldsymbol{R}^{\prime}\right]^{-1}[\boldsymbol{R} \operatorname{vec}(\widehat{\Pi})]
$$

In the equation, $\operatorname{vec}(\widehat{\Pi})$ is the (row vectorized) $2(2 p+1) \times 1$ coefficient of the ordinary least squares estimator, $\hat{\Pi}$, and $\mathbf{R}$ is the $p \times 2(2 p+1)$ matrix. Each row of $\mathbf{R}$ picks one of the coefficients to set to zero under the null hypothesis of no causality and the lagged values of $y_{2 \mathrm{t}}$ has the $\mathrm{p}$ coefficients in Eq. (2).

Following the PSY procedure, the authors develop three tests based on the supremum norm of a series of recursively evolving Wald statistics for detecting changes in causality between variables, using three different algorithms: forward recursive, rolling window, and recursive evolving window. Given that the third algorithm gives the best finite sample performance results according to some papers (Shi et al., 2018; Gharib et al., 2021) we will describe its technical details only. 
Let $f$ be the (fractional) observation of interest and $f_{0}$ be the necessary minimum (fractional) window size to estimate the model. We obtain the Wald statistic, denoted as $\mathcal{W}_{f_{2}}\left(f_{1}\right)$, for each subsample regression over $\left[f_{1}, f_{2}\right]$ with a sample size fraction of $f_{w}=f_{2}-f_{1} \geq f_{0}$ and define the sup Wald statistic as

$\mathcal{S W}_{f}\left(f_{0}\right)=\sup _{\left(f_{1}, f_{2}\right) \in \Lambda_{0}, f_{2}=f}\left\{\mathcal{W}_{f_{2}\left(f_{1}\right)}\right\}$

where $\wedge_{0}=\left\{\left(f_{1}, f_{2}\right): 0<f_{0}+f_{1} \leq f_{2} \leq 1\right.$, and $\left.0 \leq f_{1} \leq 1-f_{0}\right\}$ with the condition of $0<$ $f_{0}<1$ for some minimal sample size in the regressions. Since this procedure allows variation in the window widths, it is called the recursive evolving procedure.

Assume that $f_{b}$ and $f_{s}$ represent the origination and termination points, estimated as the first chronological observation whose test statistic is respectively greater or less than the critical value, in the causal relationship, the dating rules of recursive evolving procedure are given as

$$
\hat{f}_{b}=\inf _{f \in\left[f_{0}, 1\right]}\left\{f: \mathcal{S} \mathcal{W}_{f}\left(f_{0}\right)>\operatorname{cvr}\right\} \& \hat{f}_{s}=\inf _{f \in\left[\hat{f}_{b}, 1\right]}\left\{f: \mathcal{S} \mathcal{W}_{f}\left(f_{0}\right)<c v r\right\}
$$

where $c v r$ is the corresponding critical value of the $\mathcal{S W}_{f}$ statistic. Note that, the origination and termination dates of episode $m$ are searched, respectively, with $m \geq 2$ in the sample ranges of $\left[\hat{f}_{m-1 b}, 1\right]$ and $\left[\hat{f}_{m s}, 1\right]$.

It should be noted that the Wald statistics of the subsamples take two different forms: homoscedastic and heteroscedastic. Under the assumption of homoscedasticity, the Wald statistic can be written as

$$
\mathcal{W}_{f_{2}}\left(f_{1}\right)=\left(\boldsymbol{R} \hat{\pi}_{f_{1}, f_{2}}\right)^{\prime}\left\{\boldsymbol{R}\left[\widehat{\omega}_{f_{1}, f_{2}} \otimes\left(\sum_{t=\left\lfloor T f_{1}\right\rfloor}^{\left\lfloor T f_{2}\right\rfloor} \boldsymbol{x}_{\boldsymbol{t}} \boldsymbol{x}_{\boldsymbol{t}}^{\prime}\right)^{-1}\right]^{\boldsymbol{R}^{\prime}}\right\}^{-\boldsymbol{1}}\left(\boldsymbol{R} \hat{\pi}_{f_{1}, f_{2}}\right) .
$$

where $\mathbf{R}$ is the coefficient restriction matrix (of full row rank $d$ ) and $\hat{\pi}_{f_{1}, f_{2}}$ is the estimated coefficient population. The homoscedasticity consistent version of the sup Wald statistic is defined as

$\mathcal{S} \mathcal{W}_{f}\left(f_{0}\right)=\sup \left\{\mathcal{W}_{f_{2}}\left(f_{1}\right): f_{1} \in\left[0, f_{2}-f_{0}\right], f_{2}=f\right\}$

The heteroskedasticity consistent version of the Wald statistic and its corresponding heteroskedasticity consistent sup Wald statistic is given, respectively, by

$$
\begin{aligned}
& \mathcal{W}_{f_{2}}^{*}\left(f_{1}\right)=T_{w}\left(\boldsymbol{R} \hat{\pi}_{f_{1}, f_{2}}\right)^{\prime}\left[\boldsymbol{R}\left(\widehat{M}_{f_{1}, f_{2}}^{-1} \widehat{\Sigma}_{f_{1}, f_{2}} \widehat{M}_{f_{1}, f_{2}}^{-1}\right) \boldsymbol{R}^{\prime}\right]^{-1}\left(\boldsymbol{R} \hat{\pi}_{f_{1}, f_{2}}\right) \\
& \mathcal{S} \mathcal{W}_{f}^{*}\left(f_{0}\right)=\sup _{\left(f_{1}, f_{2}\right) \in \Lambda_{0}, f_{2}=f}\left\{\mathcal{W}_{f_{2}\left(f_{1}\right)}^{*}\right\}
\end{aligned}
$$

where $\widehat{M}_{f_{1}, f_{2}} \equiv I_{n} \otimes \hat{Q}_{f_{1}, f_{2}}$ with $\hat{Q}_{f_{1}, f_{2}} \equiv \frac{1}{T_{w}} \sum_{t=\left\lfloor T f_{1}\right\rfloor}^{\left\lfloor T f_{2}\right\rfloor} \boldsymbol{x}_{\boldsymbol{t}} \boldsymbol{x}_{\boldsymbol{t}}^{\prime}$ and $\hat{\Sigma}_{f_{1}, f_{2}} \equiv \frac{1}{T_{w}} \sum_{t=\left\lfloor T f_{1}\right\rfloor}^{\left\lfloor T f_{2}\right\rfloor} \hat{\vartheta}_{t} \hat{\vartheta}_{t}^{\prime}$ with the condition of $\hat{\vartheta}_{t}=\hat{\varepsilon}_{t} \otimes$. 


\section{Analysis and Results}

In this section, we will provide and discuss the findings of bubble detection and the LOGIT model, which are prepared in agreement with research and publication ethics.

\subsection{GSADF Test Results}

We report the findings of the GSADF tests for the weekly observations numerically in Table 2 and graphically in Figures 1.

Table 2: The PSY Test Results

\begin{tabular}{lcccc}
\hline Variables & Test Statistics & $\mathbf{0 . 1 0}$ & $\mathbf{0 . 0 5}$ & $\mathbf{0 . 0 1}$ \\
\hline XU100_TR & 2.3134 & 2.892 & 3.278 & 4.117 \\
XBANK_TR & 1.9201 & 2.660 & 3.043 & 3.822 \\
XU100_\$ & 2.1515 & 2.704 & 3.053 & 3.767 \\
XBANK_\$ & 2.5315 & 2.642 & 3.085 & 3.973 \\
BOND & $7.5141^{* * *}$ & 4.514 & 5.155 & 6.547 \\
CDS & 5.7456 & 5.899 & 7.209 & 10.267 \\
GOLD & $8.8634^{* * *}$ & 4.698 & 5.441 & 6.914 \\
USDTRY & $6.8505^{* *}$ & 5.244 & 6.187 & 8.688 \\
\hline
\end{tabular}

Notes: ${ }^{* *}$ and ${ }^{* *}$ denote rejection of the null hypothesis at the $1 \%$ and $5 \%$ significance levels, respectively. Test statistics and critical values are, respectively, obtained through the wild bootstrap approach proposed by Harvey et al. (2016) with "nboot = 5000" iterations using the R package of psymonitor (Caspi et al., 2018) and exuber (Vasilopoulos et al., 2018). Calculation of the PSY test statistic are achieved with the command PSY (y, swindow0, IC, adflag) while the bootstrapped critical values are obtained with the command radf_wb_cv $(y$, minw $=$ swindow0, nboot $=$ nboot, seed $=\mathrm{NULL})$ where " $\mathrm{y}$ " is the closing prices of underlying variable, "swindow0 = floor $\left((0.01+1.8 /\right.$ sqrt $\left.(848)){ }^{*} 848\right)$ )", "IC $=1$ (AIC)" and "adflag $=0$ ". Further, "tb $=32+$ swindow0 -1 " and "nCores $=2$ ".

As shown in the second column, the sequential ADF unit root test provides significant evidence of footprints, namely, it supports the possibility of bubbles in only three out of eight variables in the first stage as the GSADF test rejects the null of no existence of a bubble in the bond, gold, and currency markets. Our findings regarding the existence of bubbles reinforce the results of some papers for bond markets (Lamoen et al., 2017; Huston and Spencer, 2018; Chiu and Yeh, 2019), gold markets (Zhao et al., 2015; Long et al., 2016; Pan, 2018), and currency markets (Hu and Oxley, 2017; Afşar et al., 2019; Korkmaz et al., 2016). The findings regarding the nonexistence of bubbles in equity markets contradict a few papers (Chang et al., 2016; Çağli and Mandaci, 2017; Liaqat et al., 2018; Korkmaz et al., 2016) but support Çıtak (2019) and Tasci and Okuyan (2009), who argue that since Istanbul Stock Exchange (ISE) indices do not have much depth, the lack of speculative bubble may be the result of the large and relatively rational investors' precautionary behaviors. Further, the outcome related to CDS spreads concurs with the finding of Oliveira and Santos (2015), who report significant evidence of the existence of multiple periodically collapsing bubbles in SCDSs spreads in Greece.

In the second stage, we further analyze the bubble-detection findings for three markets in Figures $\mathbf{1}$. In the top panel, we plot the historical path of weekly observations for the FPI, where the periods of historic domestic and international events are demonstrated by the shadow area. The figure displays 
findings for the date-stamping strategy over the sample period, depicting the sequence of the backward SADF statistics with the solid blue line and the $95 \%$ critical values with the solid red line on the left axis, whereas the relevant time series is plotted on the right axis with the solid black line.

Apparently, we can see evidence of multiple episodes of exuberance in all asset prices during both tranquil and turmoil periods in the local or/and global economy. We begin by analyzing the bubble periods for bond yields, where the BSADF sequence exceeds the $95 \%$ critical value of 1.0475 (shaded area). We observe four genuine bubbles with a total of 40 weeks in bond markets. The first bubble emerged in the $4^{\text {th }}$ week of November and burst in the $3^{\text {rd }}$ week of December 2012, i.e. with a 4 weekly durations while the second bubble originated and terminated, respectively, in the $2^{\text {nd }}$ week and ended in the $4^{\text {th }}$ week of December 2017, i.e. with 3 weekly durations. The test detects the third obvious bubble (the largest bubble in the bond market -lasting 27 weeks- and the fifth-largest among the three markets), from May 9 to November 7, 2018, and the fourth obvious bubble originating and bursting from May 1 to June 5, 2019, coinciding with the 2018-2020 currency crisis in Turkey. During this period, the government bond rates of 2-year jumped to reach their zenith of almost 27.65 percentage points due to the political/military tensions with Trump's U.S.

Figure 1: Date-Stamping Periods of Exuberance in Bond, Gold, and Currency Markets
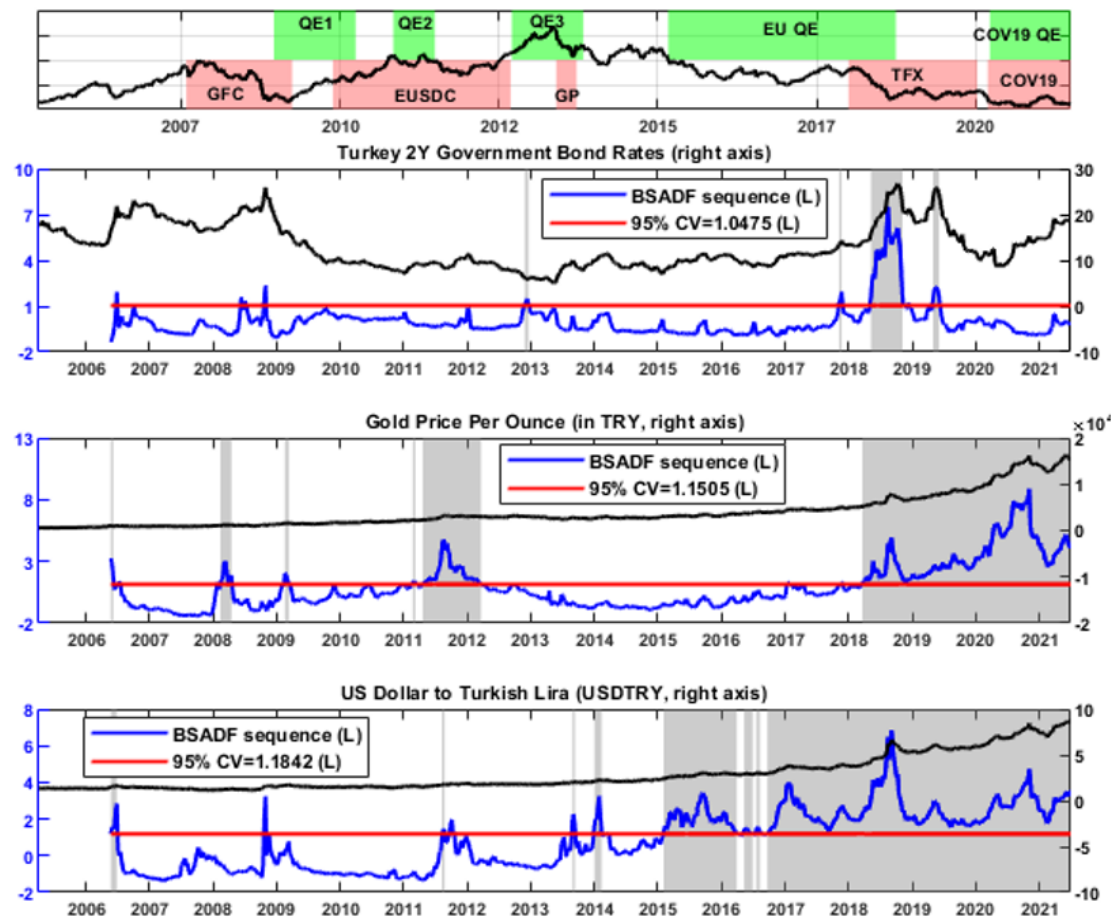

Note: The green shaded bars in the top panel represent quantitative easing periods launched by the FED and the ECB during and after the crisis periods, including financial and pandemic. Similarly, the red ones in the same panel represent the crisis periods in the US (GFC, the recent global financial crisis), the EU (EUSD, the European sovereign debt crisis), Turkey (GP, 
the Gezi Park protests and TCC, "currency and debt" crisis in Turkey), and the ongoing COVID-19 pandemic. The gray shadows in the three bottom panels are sub-periods with bubbles lasting at least 3 weeks $(>\log (T=848)=2.9)$ following the suggestions of the PWY procedure. If the corresponding BSADF test statistics in the blue solid line exceed the 95\% GSADF critical value, we conclude that the underlying time series with a green solid line has evidence of a bubble. Note that calculation of the PSY statistic sequence and the critical values can be achieved, respectively, with the commands PSY() and cvPSYwmboot() contained in the psymonitor R package.

The second panel of Figure 1 shows significant evidence of bubble existence in the Turkish gold market, where the BSADF sequence exceeds the 95\% critical value of 1.1505 (shaded area). Six bubbles are detected with a total duration of 241 weeks in the market. The first bubble episode was observed between May-June 2006, lasting three weeks. The second obvious bubble started on February, 13 and ended on March 16, 2008, coinciding with the global financial crisis around mid2008, and the third bubble -lasting 4 weeks- originated and terminated at the end of this crisis. The fourth bubble was the shortest -lasting only 3 weeks- from February to March 2011. But after five weeks, the second largest-lasting bubble with 49 weekly durations appeared, coinciding with the European sovereign debt crisis of 2009-2012 and the end of second quantitative easing launched by the FED between November 2010 and June 2011. The sixth and the largest-lasting bubble with 172 weekly durations started in March 2018, and ended in June 2021, coinciding with the Turkish currency crisis because of heightened tension between Washington and Ankara and the current pandemic crisis. These results indicate that both international and domestic events (rising inflation and depreciation of Turkish lira against other currencies) could significantly contribute to bubble occurrence in a market and, therefore, induce Turkish investors toward the safe-haven of gold as well as investing in currency, stock, cryptocurrency money, and buying real assets such as automobiles, house, etc.

The bottom panel in Figure 1 displays significant evidence of two long and six short bubble presence in the Turkish currency market, with a total duration of 342 weeks since the test statistic exceeds the right-tailed critical value of 1.1842 at the $5 \%$ significance level. The first bubble emerged in the $60^{\text {th }}$ week and ended in the $65^{\text {th }}$ week of 2006 (May-June), coinciding with the crisis period of exchange rate shocks led by rises in interest rates. Although Turkey's economy had advanced $9.6 \%$ year-on-year (YoY) in the second quarter of 2006 due to ongoing positive accelerations in the EU accession negotiations, it had been exposed to an exchange rate shock because of the increase in interest rates of the central banks of developed countries in May 2006, which had significant adverse effects on the inflation expectations and, therefore, burst the bubbles in the financial markets. Hence, total FPI in Turkey fell by $\$ 10$ billion indicating a decrease of -16.8 percent in the 2006Q3 from $\$ 59.6$ to $\$ 49.6$ billion. During the European sovereign debt crisis, the market witnessed the second bubble with a length of 3 weeks, originating and terminating in August 2011. As the test revealed, the currency market entered a bubble period with a 3 weekly duration in late August 2013, ascribing to the period when the termination date of QE3 was released by the Federal Open Market Committee (FOMC) in late 2013. This announcement and the Gezi Park protests occurring in Turkey between May 27, 2013, and September 21, 2013, were the main two drivers of the bubble formation in the currency 
market. Legitimating the arguments stated in the finance literature, the political uncertainty at the beginning of 2014 in Turkey led to the occurrence of multiple exuberances in the currency market. The test detected a bubble episode with a length of 7 weeks in the market, coinciding with the period when the CBRT increased sharply its benchmark 1-week repo interest by 550 basis points (bps) to $10 \%$ aiming to calm down the markets.

Further, it revealed another bubble formation in the USDTRY exchange rate, originating in February 2015 and collapsing at the end of March 2016. It was the second and third-largest lasting bubble in the currency and the three Turkish markets. Although a quantitative easing program was launched by the European Central Bank (ECB), initiated in March 2015 and terminated in September 2018, the Turkish lira lost 15.1 percent of its value against the US dollar during this bubble episode. We may attribute this explosive behavior to the Sah Firat operation to evacuate the Tomb of Suleyman Shah in Syria, the CBRT's policy rate cut decision from 11.25 to 10.75, terrorist attacks in Turkey, and the uncertainties regarding the general election in Turkey. After five weeks, the market again entered two bubble episodes in May and July 2016. The test finds evidence of a persistent and large bubble with a length of 8 weeks and a short-lived episode of a bubble with a length of 4 weeks.

The largest-lasting bubble in the financial markets was witnessed in the currency market between September 2016 and the end of the sample period (June 2021). We observe the longest-lived bubble formation with a length of 250 weeks, lasting about five years. The main rationale behind these bubbles before 2018 may be the surprise winning of Trump's U.S. presidential election, strengthening the USD against global currencies. We may also attribute to heightening tension between Turkey and the EU when the European Parliament called for the freezing of membership talks with Turkey, the visa crisis, and the political/military tensions with the U.S. During the 2018-2020 currency crisis driven by threatens of economic sanctions by the Trump administration on the Turkish economy, the presidential election and the renewal of local elections in Istanbul had helped to long live the bubble formation in the market. The Turkish economy was mired in stagflation in 2018, with the highest annual inflation rate of $25.24 \%$, a 15 -year high, in October 2018, and coupled with a contracting of GDP by $-2.8 \%$ (2018Q4), - 2.3\% (2019Q1), and - 1.6\% (2019Q2). This bubble did not burst in 2020 , instead, the persistent bubble behaviors continued during the pandemic era due to the rising inflation and dollarization rate. Besides, the dismissals of central bank governors before their term of office expire and the unannounced foreign-exchange sales, i.e. through back-door steps, to stabilize the lira, leading net reserves -with the swaps stripped out- to fall below zero are the other main factors that lead to the lira undervalue against the dollar.

The visual examination suggests that the explosive behaviors in the three markets mostly are encountered at different lengths and overlap during the recent local currency crisis in Turkey and the ongoing pandemic. Further, the worsening of foreign policy with the USA and the EU and local and general elections held since 2015 may cause bubbles in Turkish markets. The findings regarding the exuberance dates broadly agree with the results from Korkmaz et al. (2016) and Gharib et al. (2021) 
for gold prices; Ural (2021) and Narayan (2020) for currency markets; and Huston and Spencer (2018) and Chiu and Yeh (2019) for bond markets.

\subsection{Shi et al. Causality Test Results}

Following the procedure in Gharib et al. (2021) and Zhao et al. (2021), we also investigate the contagion effect of bubbles in financial markets by employing the recursive evolving causality test under the homoscedastic and heteroscedastic assumptions. But, before the causality testing, we must identify the integration order of the underlying variables. The findings related to the Harvey et al. (2013) test with two structural breaks for the five asset prices expressed in natural logarithms are given in Table 3.

Table 3: Harvey et al. (2013) unit root test with one and two structural breaks

\begin{tabular}{lcccc}
\hline & Level $($ Log) & \multicolumn{3}{c}{ First Difference } \\
\cline { 2 - 5 } Variable & $\mathrm{MDF}_{1}$ & $\mathrm{MDF}_{2}$ & $\mathrm{MDF}_{1}$ & $\mathrm{MDF}_{2}$ \\
\hline LN_XU100 & -3.194 & -3.217 & $-14.251^{* * *}$ & $-14.288^{* * *}$ \\
LN_BOND2 & -2.84 & -3.307 & $-8.516^{* * *}$ & $-8.573^{* * *}$ \\
LN_CDS & -3.341 & -3.461 & $-11.85^{* * *}$ & $-11.869^{* * *}$ \\
LN_GOLD & -2.253 & $-4.527^{*}$ & $-14.77^{* * *}$ & $-14.905^{* * *}$ \\
LN_USDTRY & -3.534 & $-4.324^{*}$ & $-11.299^{* * *}$ & $-11.31^{* * *}$ \\
\hline
\end{tabular}

Note: ${ }^{*},{ }^{* *}$, or ${ }^{* * *}$ indicate rejection of the null hypothesis of a unit root where the relevant critical values for MDF $_{1}$ test are $-3.57,-3.85$, and -4.40 and for $\mathrm{MDF}_{2}$ test are $-4.30,-4.58$, and -5.10 at the $10 \%, 5 \%$, and $1 \%$ significance levels, respectively.

A perusal of Table 3 shows that the null hypothesis of the existence of a unit root could be strongly rejected for "LN_GOLD" and "LN_USDTRY" in the two breaks in trend case ( $\left.\mathrm{MDF}_{2}\right)$, suggesting levelstationarity in the logarithm of prices of gold and foreign exchange rate. The findings, on the other hand, overwhelmingly reject the null hypothesis in favor of the alternative hypothesis for the series by taking the first difference in the logarithms of prices, indicating that all series seem to be trend-stationary at the $1 \%$ significance level. Thus, the weekly prices of all variables are used for the causality test.

Identifying changes in the causal linkages as well as contagion effect of bubbles in the financial markets, we implement the recursive evolving causality test and display the results, along with the relevant bootstrapped critical values at the 5\% significance level, in Figures 2 and 3. Note that, in estimating the bivariate VAR model and performing causality test for all subsamples, the optimal lag length (1) is determined through the Bayesian information criterion (BIC) with the maximum lag length of 12 . The critical values are obtained from a bootstrapping procedure with 499 replications and the empirical size is controlled over 32 weeks, simulating $M=169+32$ (contrsize) $-1=200$ observations for each bootstrapped sample.

The findings for testing the time-variant causality between the XU100 prices and 2-year government bond yields under the homoscedastic and heteroscedastic assumptions are given in the top and bottom panels in Figure 2. The Wald test statistic and the $5 \%$ critical value are indicated by a solid 
black and horizontal dashed red line, respectively. Therefore, when the rolling window (M) test statistics (solid line) exceed the critical value (dashed line), then a significant change in causality is detected.

Figure 2: Shi et al. (2018) Recursive Evolving Causality Relationship Between XU100 and BOND2 Under Two Models
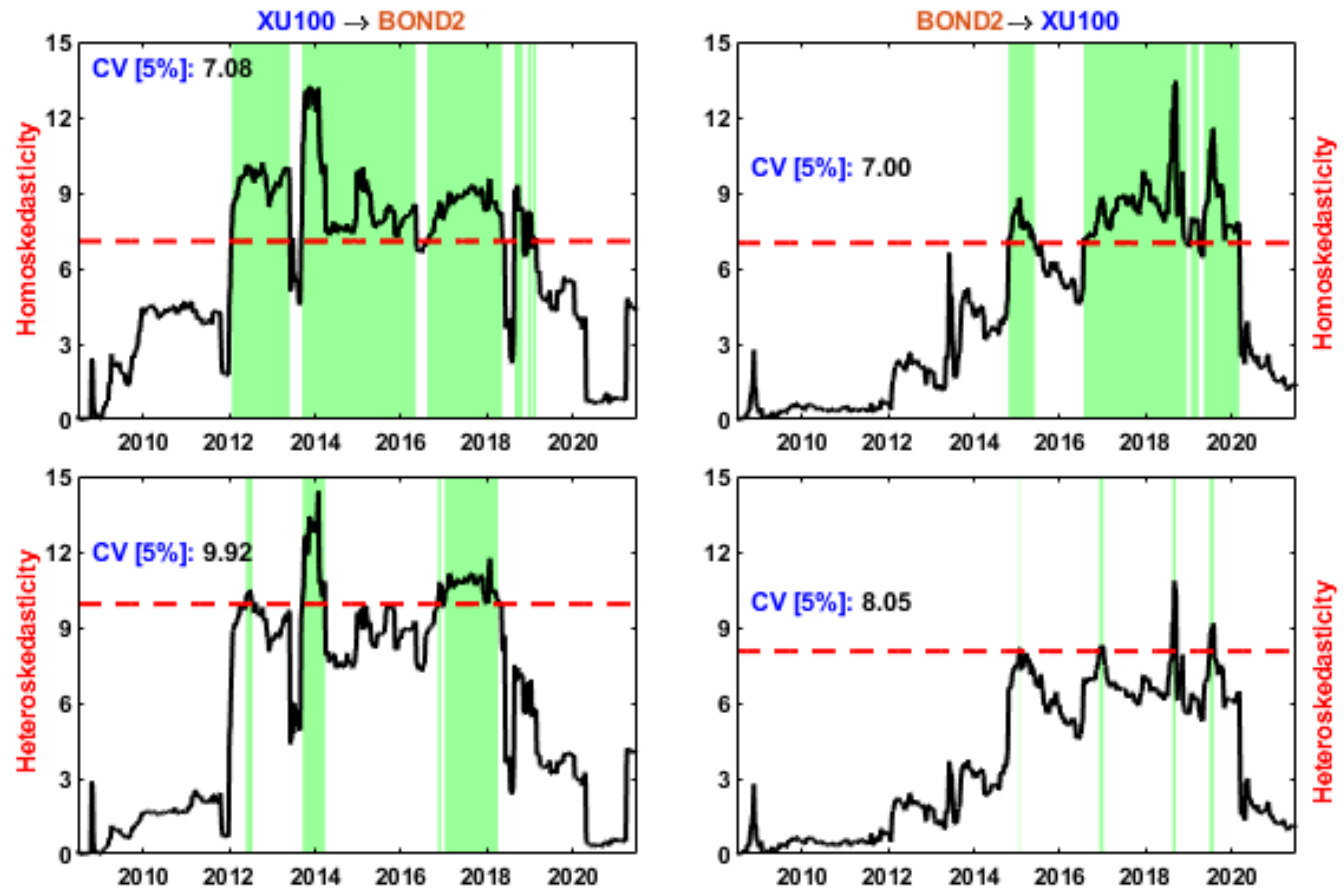

Note: The parameters for the causality are defined as $\mathrm{d}=1$ (the integration order), $\mathrm{x}=0, \mathrm{f} 0=0.20$, contrsize $=32$, IC_flag $=20$, alpha $=0.95$, and $\mathrm{M}=$ floor $\left(\mathrm{fO}^{*} \mathrm{nob}\right)+$ contrsize -1 (in the main function) and nboot $=499$ (in the boostrap_RGC_ MW.m). The green bar in plots shows the periods where the null hypothesis is rejected at the $5 \%$ significance level under the homoscedastic (top) and heteroscedastic (bottom) assumptions.

The top panel shows seven periods of significant Granger causal flows from XU100 index to bond yields, lasting 324 weeks (the largest episode of causality is 139 weeks), whereas it displays four periods for the reverse direction, lasting 214 weeks (the largest episode of causality is 126 weeks) under the homoscedastic assumption. For example, the recursive evolving approach finds evidence of Granger causality running from XU100 index to bond yields, $X \rightarrow B$ (see Figure 3), from January 25, 2012, to May 29, 2013, and from September 11, 2013, to October 15, 2014. The causality turns out to be bidirectional from this week until June 2016. Again, the results indicate a unidirectional causality, $X \rightarrow B$, from June 10, 2015 to May 4, 2016. The reverse causal relationship, $B \rightarrow X$, has been found for three weeks from July to August 2016. From this week, it shows a feedback causal relationship until May 9, 2018. 
Figure 3: Shi et al. (2018) Recursive Evolving Causality Test Under the Homoscedasticity Assumption

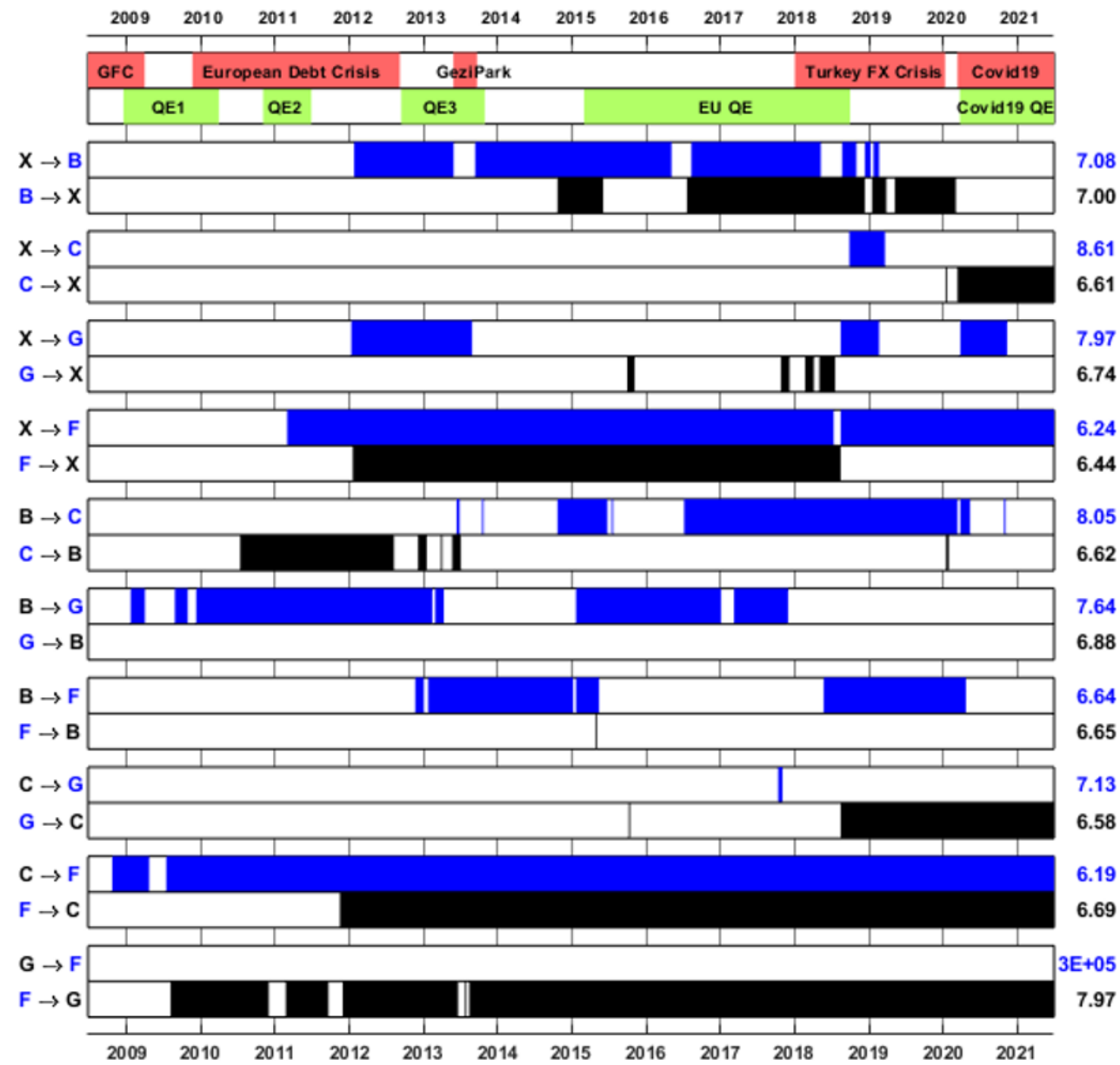

Notes: X, B, C, G, and F stand for, respectively, the changes in "XU100", "Bond", “CDS", "GOLD", and "USDTRY". Each causality model is represented at the left hand, as, $X \rightarrow B$, for example, while the critical value of $5 \%$ significance levels is given at the right hand of each panel. The shaded region shows the week during which the test is statistically significant at the $5 \%$ level. The blue (black) bars show the intervals where the Wald test statistic exceeds its relevant critical values for $x \rightarrow y$ $(\mathrm{y} \rightarrow \mathrm{x})$ when the subsample $(\mathrm{M})$ is 200 .

Between the period May-August 201, bond yields Granger-cause XU100. Again, bidirectional causality occurs from the fourth week of August to the last week of October 2018. During the next five weeks, bond yields exert significant one-way causal effects on the stock index. However, stock index Granger - causes bond yields unidirectionally from December 2018 to January 2019 with four weeks duration. Later, the causality is bidirectional from January 23 to February 20, 2019, but, it seems to be unidirectional, $B \rightarrow X$, from then until the end of March 2019 and from May 8, 2019, to 
March 04, 2020, with no reverse direction. Looking at the bottom panel, we see that the episodes of causality under the heteroscedastic assumption entirely synchronize with the episodes of causality under the homoscedastic assumption, but the periods are shorter than that of the second assumption. The findings are moderately in line with Gök (2020) and Gök and Çankal (2020) for the causality relationship of $B \rightarrow X$.

In the next figure, we show the causality relationship among all financial asset prices under the homoscedastic assumption, using blue bars for the causality relationship, for example, of $X \rightarrow C$ and black bars for the reverse direction, $C \rightarrow X$ second panel from above. The recursive evolving approach detects two causality episodes from XU100 to CDS, lasting 27 weeks, and three causality episodes for the reverse direction, lasting 72 weeks. The causality relationship, $X \rightarrow C$, lasts only one week in September 2018 but significant evidence re-emerged at the end of this month until the third week of March 2019 during the currency crisis in Turkey. From January 15 to 22, 2020, and at the third week of February 2020, the causality reverses, and CDS spreads Granger-cause stock index. The direction of causality does not change from the second week of March 2020 to the end of the sample period during the COVID-19 pandemic, indicating that the movements in CDS spreads are influential factors in predicting future stock prices in Turkey. The results contradict Gök (2020) and Noorie et al. (2020), who do not find any significant evidence of causality.

The next panel of Figure 3 shows that the test identifies three causality episodes from XU100 to Gold, $X \rightarrow G$, lasting 148 weeks, and five causality episodes for the reverse direction, $G \rightarrow X$, lasting 33 weeks. For the first case, the first episode lasts 86 weeks from January 11, 2012, to August 28, 2013; the second lasts 28 weeks, starting on August 15, 2018, and ending on February 20, 2019; and the third lasts 34 weeks, from March 25 to November 11, 2020. These episodes coincide with the Eurozone sovereign debt crisis and the Gezi Park protests, the currency, and the pandemic crisis, respectively. For the reverse direction, $G \rightarrow X$, the procedure detects five episodes of causality, lasting six, seven, one, seven, and twelve weeks during the EU quantitative easing and the currency crisis in Turkey. These findings are consistent with the empirical evidence reported in Gök (2020) and Yamaka and Maneejuk (2020), who found one-way or two-way causal linkages between gold and stock markets during the crisis and non-crisis periods.

Next, we detect two long for $X \rightarrow F$ and one long period of causality for $F \rightarrow X$, lasting 536 and 344 weeks, respectively. The null hypothesis can be strongly rejected since the test statistic sequence exceeds the $95 \%$ critical value of 6.24 for $X \rightarrow F$ and 6.44 for the reverse direction. The recursive evolving approach finds evidence of Granger causality running from the XU100 index to the foreign exchange rate of USDTRY from March 2, 2011, to January 11, 2012. After this week, the direction of causality seems to be bidirectional until July 11, 2018, lasting 339 weeks. During the next four weeks, the direction is changing as $\mathrm{F} \rightarrow \mathrm{X}$. From the following week, the causality running from XU100 to USDTRY remains until the end of the sample period, lasting 150 weeks and coinciding with the recent currency and ongoing pandemic crisis. In line with our results, Kanda et al. (2018) find evidence of time-varying causality between the stock and currency market returns for India and South Africa during the recent financial crisis. 
There are seven and eight episodes of Granger causality for the $B \rightarrow C$ relationship and in the reverse direction, $C \rightarrow B$, lasting 246 and 131 weeks, respectively. During the European debt crisis, we find that CDS spreads Granger-cause bond yields from July 2010 to August 2018 - the most longlasting episode with 109 weeks. The findings reveal some shorter periods of unidirectional causality from December 2012 to June 2013, with several small breaks. During June 2013, the causality is bidirectional, coinciding with the Gezi Park protests in Turkey. From this date, the direction of causality remains the same, that is, bond yields Granger-cause CDS spreads from July 2016 to the onset of the COVID-19 pandemic. One week later, another episode of causality emerges until the second week of May 2020. The last episode lasts only two weeks, originating at the end of October and terminating at the beginning of November 2020. The results concur with the finding of Delis et al. (2011) and Gök and Kara (2021), who find a time-varying but unidirectional or bidirectional causality between those markets during the periods of debt and pandemic crises.

For the CDS-gold pair, the procedure detects one short causality episode for the $C \rightarrow G$ relationship, lasting 4 weeks, and two short and one long episode for the $G \rightarrow C$ relationship, lasting two, one, and 151 weeks. The most long-lasting episode, running from gold to CDS, begins on August 15, 2018, and continues until the end of the sample period. The results are partly inconsistent with Gök's (2020) findings, who finds significant unidirectional causality from CDS to gold but detect unidirectional lead-lag relationship during the different time periods, coinciding the crisis periods other than that of the financial crisis of 2007-2009, using the static causality and the wavelet coherency approaches.

The recursive evolving test identifies two and one long causality episode for $C \rightarrow F$ and $F \rightarrow C$ relationships, lasting 652 and 503 weeks, respectively. Since the time-variant Wald statistics exceed the critical value of 6.19, we observe one episode of unidirectional causality running from CDS to USDTRY during the global financial crisis. Likewise, from July 15, 2009, to November 9, 2011, there exists a one-way causality, but, then it turns out to be bidirectional and the type of causality remains unchanged until the end of the sample period. The results suggest that the movements in CDS can be predicted through the use of the currency market, during the episodes of financial and debt crises. As of November 2011, however, a feedback relationship emerges between those most sensitive markets to local and global developments. The results are consistent with the findings of Hassan et al. (2017) and Gök and Kara (2021), who reveal time-varying unidirectional/bidirectional causalities during the crisis and non-crisis periods.

Next, we investigate time-varying and the contagion effect of bubbles among three financial markets, i.e. bond, gold, and currency. By following Zhao et al. (2021), we compare the time, duration, and size of the bubbles in those markets and the results reveal evidence of contagion effects from the currency market to the others during the local currency and COVID-19 pandemic crises. For the bond-gold pair, for example, a visual inspection suggests that the causality seems to be running from bond yields to gold prices -with seven episodes and lasting 338 weeks- and not the other way around. As the times of bubbles and causal episodes do not match during the sample period, we may interpret this result as no contagion effect of bubbles between bond and gold markets. For the bond-currency markets pair, however, the procedure detects four causal episodes, lasting 228 weeks, for $\mathrm{B} \rightarrow \mathrm{F}$ relationships, 
from November 2012 to May 2015 -with some small breaks- and May 23, 2015, to April 22, 2020. The causality is bidirectional for two weeks in May 2015. The results may be interpreted as a bilateral contagion effect of the bubble in bond and currency markets during the currency crisis since the times of bubbles and causal episodes do overlap around mid-2018. For the returns of gold-currency pair ( $d$ is set to zero due to their integration order, $I(0))$, the results suggest evidence of unidirectional causality running from currency returns to gold returns, with five episodes lasting 597 weeks. USDTRY exchange rates unidirectionally cause gold prices in TL from August 5, 2009, to the first week of December 2010; from February 23, 2011, to September 21, 2011; from the end of November 2011 to June 19, 2013; from the fourth to fifth week of July 2013; and from August 14, 2013 (during the last weeks of Gezi Park protests in Turkey) to the end of the sample period. Since the times of bubbles and causal episodes overlap during the currency and pandemic crisis, we may interpret this result as the unidirectional contagion effect of bubbles in the currency to the gold market.

The results regarding the causality test under the heteroscedastic assumption, not presented here but available from the author upon request, shows that the causality episodes are shorter than that of the findings given in the previous figure, that is, there is no significant difference between the results under two assumptions.

\section{Conclusion and Discussion}

In this paper, we tried to answer the questions of whether the Turkish asset prices feature bubble like-characteristics through the right-tailed unit root (GSADF) test using weekly averages for the sample period of 2005-2021. The answer is no for five out of eight variables, namely, the test strongly rejected the existence of bubble formations in stock (4) and CDS markets. Corroborating previous findings, the results showed evidence of bubbles in the currency, gold, and bond markets during both turmoil and tranquil periods, confirming the existing literature like $\mathrm{Hu}$ and Oxley (2017), Korkmaz et al. (2016), Zhao et al. (2015), Pan (2018), and Lamoen et al. (2017), etc., indicating divergence of Turkish asset prices from their market fundamentals. Furthermore, the role of gold as a safehaven was confirmed for Turkish investors during the currency and COVID-19 pandemic crises. We observed that bubbles in the currency market were more frequent and had a longer duration than the others, pointing to the lesser efficiency in this market. On the other hand, the estimation of the recursive evolving Granger causality test documented evidence of unidirectional and bidirectional causalities among financial markets under the homoscedastic and heteroscedastic assumptions. Compared with the duration of causal episodes, the findings under the homoscedastic assumption outperform and yield better finite sample performance than that of the heteroscedastic assumptionbased estimation. The causation is most pronounced under the homoscedastic assumption between the currency market with the CDS, gold, and stock markets. Finally, we detect a unidirectional and bilateral contagion effect of bubbles in the currency market to bond and gold markets during the currency and pandemic crises.

The results have significant implications for policymakers in attaining price and financial stability and investors for risk and portfolio management as well as arbitrage opportunities, as the existence of 
a bubble in a market could create disruptive effects on an economy through redistribution of wealth (Jahan-Parvar and Waters, 2010; Elike and Anoruo, 2017). Given that GSADF tests could be used as a real-time bubble detector (Homm and Breitung, 2012), implementation of this approach and the time-varying causality tests by policymakers could provide important benefits in terms of assessing and measuring risks driven by exogenous or/and endogenous shocks, and taking preemptive measures in the markets. On the other hand, they need to be aware of the contagion effect of bubbles between markets and should follow appropriate policies, such as tightening monetary policy and decreasing the aggregate demand, in the case of a bubble formation, to minimize real and financial consequences. Investors, on the other hand, should react rationally to price movements and content themselves with a reasonable rate of return without changing their degree of risk aversion during the bubble episodes and, therefore, leaving the market before the collapse. We conclude that taking account of psychological and political factors affecting bubble formation in the markets warrants future research.

\section{References}

Afşar, M., Afşar, A., \& Doğan, E. (2019). Döviz balonlarinin tespitine yönelik bir analiz: Türkiye örneği. Erciyes Üniversitesi İktisadi ve İdari Bilimler Fakültesi Dergisi, 54, 447-460.

Balcilar, M., Gupta, R., Jooste, C., \& Wohar, M. E. (2016). Periodically collapsing bubbles in the South African stock market. Research in International Business and Finance, 38, 191-201.

Baur, D. G. \& Glover, K. (2012). A gold bubble? SSRN Electronic Journal Retrieved from http://papers.ssrn.com/ sol3/papers.cfm?abstract_id=2166636.

Bertus, M. \& Stanhouse, B. (2001). Rational speculative bubbles in the gold futures market: an application of dynamic factor analysis. Journal of Futures Markets: Futures, Options, and Other Derivative Products, 21(1), 79-108.

Bettendorf, T. \& Chen, W. (2013). Are there bubbles in the sterling-dollar exchange rate? New evidence from sequential ADF tests. Economics Letters, 120(2), 350-353.

Bialkowski, J., Bohl, M. T., Stephan, P. M., \& Wisniewski, T. P. (2015). The gold price in times of crisis. International Review of Financial Analysis, 41, 329-339.

Blanchard, O. J. \& Watson, M. W. (1982). Bubbles, rational expectations and financial markets. U.S. National Bureau of Economic Research (NBER) Reports, No. 0945.

Brunnermeier, M. K. (2008). Bubbles. In Lawrence Blume and Durlauf, Steven (Eds.), New Palgrave Dictionary of Economics, Second Edition (pp. 1-16). London, UK: Palgrave Macmillan. Retrieved from http:// scholar.princeton.edu/sites/default/files/bubbles_survey_0.pdf

Caspi, I., Phillips, P. C. B., \& Shi, S. (2018). Real time monitoring of asset markets with psymonitor. R package version 0.0.1. URL: https://itamarcaspi.github.io/psymonitor

Chan, H. L., Lee, S. K., Woo, \& K. Y. (2003). An empirical investigation of price and exchange rate bubbles during the interwar European hyperinflations. International Review of Economics Finance, 12(3), 327344.

Chang, T., Gil-Alana, L., Aye, G. C., Gupta, R., \& Ranjbar, O. (2016). Testing for bubbles in the BRICS stock markets. Journal of Economic Studies, 43(4), 646-660.

Chiu, C. L. \& Yeh, C. C. (2019). Whether the multiple bubbles exist in the bond markets of developed countries? International Journal of Information and Management Sciences, 30(2019), 271-282. 
Çağlı, E. Ç. \& Mandacı, P. E. (2017). Borsa İstanbul'da rasyonel balon varlı̆̆ı: sektör endeksleri üzerine bir analiz. Finans Politik Ekonomik Yorumlar, 54(629), 63-76.

Çelik, I., Akkuş, H. T., \& Gülcan, N. (2019). Investigation of rational bubbles and volatility spillovers in commodity markets: evidences from precious metals. Mehmet Akif Ersoy Üniversitesi İktisadi ve İdari Bilimler Fakültesi Dergisi, 6(3), 936-951.

Çıtak, F. (2019). Türkiye hisse senedi piyasasinda spekülatif balon varliğinin ampirik incelenmesi. Uluslararası Ekonomi ve Yenilik Dergisi, 5(2), 247-262.

Deev, O., Kajurová, V., \& Stavárek, D. (2014). Rational speculative bubbles in central European emerging stock markets. Eastern European Economics, 52(4), 47-91.

Delis, M. D. \& Mylonidis, N. (2011). The chicken or the egg? A note on the dynamic interrelation between government bond spreads and credit default swaps. Finance Research Letters, 8(3), 163-170.

Diba, B. T. \& Grossman, H. I. (1984). Rational bubbles in the price of gold. U.S. National Bureau of Economic Research (NBER) Reports, No. 1300.

Diba, B. T. \& Grossman, H. I. (1988). Explosive rational bubbles in stock prices? The American Economic Review, 78(3), 520-530.

El-Montasser, G., Fry, J., \& Apergis, N. (2016). Explosive bubbles in the US-China exchange rate? Evidence from right-tailed unit root tests. China Economic Journal, 9(1), 34-46.

Elike, U. \& Anoruo, E. (2017). Testing for explosive bubbles in the south African-US exchange rate using the sequential ADF procedures. Banks and Bank Systems, 12(1), 105-112.

Evans, G. W. (1986). A test for speculative bubbles in the sterling-dollar exchange rate: 1981-84. The American Economic Review, 76(4), 621-636.

Evans, G. W. (1991). Pitfalls in testing for explosive bubbles in asset prices. The American Economic Review, 81(4), 922-930.

Froot, K. \& Obstfeld, M. (1991). Intrinsic bubbles: the case of stock prices. American Economic Review, 81, 1189-1214.

Gharib, C., Mefteh-Wali, S., \& Jabeur, S. B. (2021). The bubble contagion effect of COVID-19 outbreak: Evidence from crude oil and gold markets. Finance Research Letters, 38, 101703.

Gök, R. \& Kara, E. (2021). Testing for causality among cds, interest, and exchange rates: new evidence from the granger coherence analysis. Eskişehir Osmangazi Üniversitesi İktisadi ve İdari Bilimler Dergisi, 16(2), $427-445$.

Gök, R. (2020). Causality between stock market and macroeconomic variables in Turkey: new evidence from wavelet coherence analysis. Erciyes Üniversitesi İktisadi ve İdari Bilimler Fakültesi Dergisi, 56, 229-254.

Gök, R. \& Çankal, E. (2020). Granger causal relationship between bond yield changes and equity returns through wavelets analysis: The case of Turkey. Ege Academic Review, 20(4), 301-317.

Gomez-Gonzalez, J. E., Ojeda-Joya, J. N., Franco, J. P., \& Torres, J. E. (2017). Asset price bubbles: existence, persistence and migration. South African Journal of Economics, 85(1), 52-67.

Gürkaynak, R. S. (2008). Econometric tests of asset price bubbles: taking stock. Journal of Economic Surveys, 22(1), 166-186.

Hall, S. G., Psaradakis, Z., \& Sola, M. (1999). Detecting periodically collapsing bubbles: a markov-switching unit root test. Journal of Applied Econometrics, 14(2), 143-154.

Harvey, D. I., Leybourne, S. J., Sollis, R., \& Taylor, A. R. (2016). Tests for explosive financial bubbles in the presence of non-stationary volatility. Journal of Empirical Finance, 38, 548-574.

Harvey, D. I., Leybourne, S. J., \& Taylor, A. R. (2013). Testing for unit roots in the possible presence of multiple trend breaks using minimum Dickey-Fuller Statistics. Journal of Econometrics, 177(2), 265-284. 
Hassan, M. K., Kayhan, S., \& Bayat, T. (2017). Does credit default swap spread affect the value of the Turkish lira against the US dollar? Borsa Istanbul Review, 17(1), 1-9.

He, Q., Qian, Z., Fei, Z., \& Chong, T. T. L. (2019). Do speculative bubbles migrate in the Chinese stock market? Empirical Economics, 56(2), 735-754.

Homm, U. \& Breitung, J. (2012). Testing for speculative bubbles in stock markets: a comparison of alternative methods. Journal of Financial Econometrics, 10(1), 198-231.

Hu, Y. \& Oxley, L. (2017). Are there bubbles in exchange rates? Some new evidence from G10 and emerging market economies. Economic Modelling, 64, 419-442.

Huston, J. H. \& Spencer, R. W. (2018). Quantitative easing and asset bubbles. Applied Economics Letters, 25(6), 369-374.

Jahan-Parvar, M. R. \& Waters, G. A. (2010). Equity price bubbles in the middle eastern and north African financial markets. Emerging Markets Review, 11(1), 39-48.

Jalan, A., Matkovskyy, R., \& Potì, V. (2021). Shall the winning last? A study of recent bubbles and persistence. Finance Research Letters, Article e102162.

Jiang, C., Wang, Y., Chang, T., \& Su, C. W. (2015). Are there bubbles in Chinese RMB-dollar exchange rate? evidence from generalized sup ADF tests. Applied Economics, 47(56), 6120-6135.

Jirasakuldech, B., Emekter, R., \& Went, P. (2006). Rational speculative bubbles and duration dependence in exchange rates: an analysis of five currencies. Applied Financial Economics, 16(3), 233-243.

Kanda, P., Burke, M., \& Gupta, R. (2018). Time-varying causality between equity and currency returns in the United Kingdom: evidence from over two centuries of data. Physica A: Statistical Mechanics and its Applications, 506, 1060-1080.

Korkmaz, Ö. (2018). The relationship between bitcoin, gold, foreign exchange returns: the case of Turkey. Turkish Economic Review, 5(4), 359-374.

Korkmaz, Ö., Erer, D., \& Erer, E. (2016). Alternatif yatırım araçlarında ortaya çıkan balonlar Türkiye hisse senedi piyasasını etkiliyor mu? BIST100 üzerine bir uygulama. BDDK Bankacılık ve Finansal Piyasalar Dergisi, 10(2), 29-61.

Lamoen, R., Mattheussens, S., \& Dröes, M. (2017). Quantitative easing and exuberance in government bond markets: evidence from the ECB's expanded asset purchase program. De Nederlandsche Bank Working Paper. No. 548.

Liaqat, A., Nazir, M. S., \& Ahmad, I. (2018). Identification of multiple stock bubbles in an emerging market: application of GSADF approach. Economic Change and Restructuring, 52(3), 301-326.

Long, W., Li, D., \& Li, Q. (2016). Testing explosive behavior in the gold market. Empirical Economics, 51(3), 1151-1164.

Maldonado, W. L., Ribeiro, J., \& Tourinho, O. A. F. (2019). Testing four types of bubbles in BRICS exchange rates. Emerging Markets Finance and Trade, 1-21.

Meese, R. A. (1986). Testing for bubbles in exchange markets: a case of sparkling rates? Journal of Political Economy, 94(2), 345-373.

Narayan, P. K. (2020). Did bubble activity intensify during COVID-19? Asian Economics Letters, 1(2).

Nazir, M. S., Mahmood, J., Abbas, F., \& Liaqat, A. (2019). Do rational bubbles exist in emerging markets of SAARC? Journal of Economic and Administrative Sciences. 36(2), 163-182.

Noorie, S., Meriç, E., Yildirim, S., \& Esen, E. (2020). Analysis of the relationship between macroeconomic variables and BIST-30 stock returns. Business \& Management Studies: An International Journal, 8(4), 500-522. 
Oliveira, M. A., Santos, C. (2015). Market exuberance in sovereign credit default swaps: assessing the EU regulatory framework and trading profit opportunities. Investment Management and Financial Innovations, 12(4), 70-80.

Pan, W. F. (2018). Sentiment and asset price bubble in the precious metals markets. Finance Research Letters, $26,106-111$.

Pavlidis, E. G., Paya, I., \& Peel, D. A. (2017). Testing for speculative bubbles using spot and forward prices. International Economic Review, 58(4), 1191-1226.

Phillips, P. C., Shi, S., \& Yu, J. (2015). Testing for multiple bubbles: historical episodes of exuberance and collapse in the SP500. International Economic Review, 56(4), 1043-1078.

Phillips, P. C., Wu, Y., \& Yu, J. (2011). Explosive behavior in the 1990s NASDAQ: when did exuberance escalate asset values? International Economic Review, 52(1), 201-226.

Phillips, P. C. \& Yu, J. (2011). Dating the timeline of financial bubbles during the subprime crisis. Quantitative Economics, 2(3), 455-491.

Shi, S., Phillips, P. C., \& Hurn, S. (2018). Change detection and the causal impact of the yield curve. Journal of Time Series Analysis, 39(6), 966-987.

Shiller, R. J. (1981). Do stock prices move too much to be justified by subsequent changes in dividends? American Economic Review, 71, 421-436.

Taşç1, H. M. \& Okuyan, H. A. (2009). İMKB'de spekülatif şişkinlerin test edilmesi. Doğuş Üniversitesi Dergisi, $10(2), 272-283$.

Tran, T. B. N. (2017). Speculative bubbles in emerging stock markets and macroeconomic factors: a new empirical evidence for Asia and Latin America. Research in International Business and Finance, 42, 454-467.

Ural, M. (2021). Analyzing multiple bubbles in the USDKZT exchange rate using the GSADF test. Eurasian Research Journal, 3(2), 7-18.

Vasilopoulos, K., Pavlidis, E., \& Spavound, S. (2018). Econometric Analysis of Explosive Time Series. R Foundation for Statistical Computing. Vienna, Austria. URL: https://github.com/kvasilopoulos/exuber

West, K. D. (1987). A specification test for speculative bubbles. The Quarterly Journal of Economics, 102(3), 553-580.

$\mathrm{Wu}, \mathrm{Y}$. (1995). Are there rational bubbles in foreign exchange markets? evidence from an alternative test. Journal of International Money and Finance, 14(1), 27-46.

Yamaka, W. \& Maneejuk, P. (2020). Analyzing the causality and dependence between gold shocks and Asian emerging stock markets: a smooth transition copula approach. Mathematics, 8(1), 120.

Yanık, S. \& Aytürk, Y. (2011). Rational speculative bubbles in Istanbul stock exchange. Muhasebe ve Finansman Dergisi, 51, 175-190.

Yu, J. S. \& Hassan, M. K. (2010). Rational speculative bubbles in MENA stock markets. Studies in Economics and Finance, 27(3), 247-264.

Zeren, F., Yllancı, V. (2019). Are there multiple bubbles in the stock markets? further evidence from selected countries. Ekonomika (Economics), 98(1), 81-95.

Zhao, Y., Chang, H. L., Su, C. W., \& Nian, R. (2015). Gold bubbles: when are they most likely to occur? Japan and the World Economy, 34, 17-23.

Zhao, Z., Wen, H., \& Li, K. (2021). Identifying bubbles and the contagion effect between oil and stock markets: new evidence from China. Economic Modelling, 94, 780-788. 